\title{
Selective Surfaces of Ilmenite for Use in Solar Absorbers
}

\author{
Gustavo César Pamplona de Sousa ${ }^{a *}$ (D), Kelly Cristiane Gomes ${ }^{a, b}$ (D), \\ Wanderley Ferreira de Amorim Júniorc, Raimundo Nonato Calazans Duarte ${ }^{c}$ \\ ${ }^{a}$ Universidade Federal da Paraíba (UFPB), Programa de Pós-Graduação em Engenharia Mecânica, \\ João Pessoa, PB, Brasil \\ ${ }^{b}$ Universidade Federal da Paraiba (UFPB), Departamento de Engenharia de Energias Renováveis, \\ João Pessoa, PB, Brasil \\ ${ }^{c}$ Universidade Federal de Campina Grande (UFCG), Unidade Acadêmica de Engenharia Mecânica, \\ Campina Grande, PB, Brasil
}

Received: August 07, 2020; Revised: October 29, 2020; Accepted: November 27, 2020

\begin{abstract}
The world is moving at a fast pace in the consumption of non-renewable natural resources, causing several ecological problems. The search for the cost reduction by implementing renewable energies implies in the optimization of the manufacturing processes parameters of consolidated technologies, such as solar thermal energy collectors. One of the applications of selective surfaces is to improve performance of solar absorbers. The purpose of this work is to produce selective coatings with high absorption in range of UV/Vis and low emittance in the IR range. It was prepared a selective surface composed of ilmenite deposited on substrates of AISI 304 stainless steel using technique of cathodic cage plasma nitriding/deposition for application in solar thermal absorbers. Ilmenite was initially characterized by X-Ray Diffractometry (XRD), X-Ray Fluorescence (FRX) and Thermal Analysis (TGA). The coatings produced were optically characterized in range UV/Vis/IR and emittance and data on the roughness parameters of the films were obtained by Optical Profilometry. Selective surfaces with high solar absorbance (87\%) compared with state-of-the-art commercial ones $(70-80 \%)$ and low thermal emission (14\%) compared with state-of-the-art commercial ones (20-30\%) were obtained by validating the potential of ilmenite to produce selective surfaces for thermal solar collectors.
\end{abstract}

Keywords: selective surfaces, solar absorbers, ilmenite, hollow cathode deposition.

\section{Introduction}

Most of the energy used by humanity comes from fossil fuels, and the use of such energies, on a large scale, has considerably changed the environmental conditions of the planet. The study of renewable sources of energy has become extremely relevant ahead of the growing world demand for energy ${ }^{1}$. Among these sources, solar energy stands out. One of its forms of exploitation is using solar collectors, which promote the conversion of solar energy into thermal energy ${ }^{2}$. The efficiency of these collectors is compromised due to a large loss from the emission of thermal radiation, resulting in operating temperatures below $100^{\circ} \mathrm{C}$ and limiting their applicability ${ }^{3}$. An effective method to increase the performance of a collector is incorporate a selective (spectral) wavelength surface for the absorber. The selective surfaces absorb the maximum possible radiation in the ultraviolet, visible and near infrared (UV-Vis-NIR) range of the electromagnetic spectrum $^{4}$, while emitting little in the medium and distant infrared region, that is, they have absorption above $85 \%$ and emission below $15 \%$ in the mentioned wavelength bands ${ }^{5}$.

Absorptivity is the ratio of the amount of radiation absorbed by a solid to the amount of radiation incident to that solid. Thus, when the intention is to evaluate the

*e-mail address: gomes@cear.ufpb.br absorptivity of a solid in the radiation range comprising the solar spectrum, it is necessary to evaluate how much of this radiation is absorbed by the solid. This parameter can be calculated from Equation $1^{6}$, shown below.

$$
\alpha=\frac{\int_{300}^{2500} \alpha_{\lambda} I_{\mathrm{sol}} \mathrm{d} \lambda}{\int_{300}^{2500} I_{\mathrm{sol}} \mathrm{d} \lambda}
$$

Considering that radiation absorption is a surface phenomenon of the material, many techniques are being studied for the deposition of the material, with favorable optical properties, on the substrate. The hollow cathode plasma nitriding/deposition is an adaptation of ionic nitriding technique to reduce undesirable problems of the conventional process, mainly obtaining a homogeneous film ${ }^{7}$. This technique uses a discharge produced between close enough cathodes to produce an intensification of ionic density due to the trapping of electrons between the electrodes ${ }^{7}$. Ions generated by collision with electrons in this region, will be accelerated to the electrodes, producing localized heating, sputtering and atomic diffusion.

One of the variables that must be considered, when it is intended to improve efficiency and minimize the costs of a thermal conversion system in collectors, is the choice 
of selective material. Ilmenite $\left(\mathrm{FeTiO}_{3}\right)$ is a common and abundant iron and titanium oxide in the world. With theoretical composition of $\mathrm{Fe}(36.8 \%)$, $\mathrm{Ti}(31.6 \%)$ and $\mathrm{O}(31.6 \%)$, ilmenite is a typically opaque mineral, characterized by conducting bands of iron and titanium oxides that extend across the spectrum ${ }^{8}$. This crystalline structure was previously studied by Barth and Posnjak ${ }^{9}$ and gained high scientific interest over the years, both for its mineralogical importance and for its technological applications around pigmentation and photocalizers ${ }^{10}$.

In view of the great abundance of the ilmenite mineral, added to the fact that the production of pure metallic titanium implies the use of sophisticated chemical processes and high cost, there is a need to develop research in order to increase the applications of minerals derivatives of that metal. The goal of this work is to evaluate the potential of ilmenite as a selective surface of solar thermal collectors.

To assess the optical behavior of a solid material in relation to a specific range of the electromagnetic spectrum of radiation (solar radiation, for example), it is necessary to define measurable physical quantities that will define the response of this material to this radiation ${ }^{11}$. Such quantities are called optical properties of materials and are grouped into four types: absorptivity, reflectivity, transmissivity, and emissivity. In general, the incident thermal radiation must be reflected out of the medium, absorbed inside the layer or transmitted through the surface ${ }^{12}$. Emissivity is the body's ability to radiate the absorbed heat and is defined as the ratio between the radiation emitted by the solid and the radiation emitted by a black body at the same temperature. Considering the solid to be opaque, his emissivity can be calculated from Equation $2^{6}$, shown below.

$$
\varepsilon=\frac{\int_{2500}^{100000}\left(1-\rho_{\lambda}\right) I_{b} \mathrm{~d} \lambda}{\int_{2500}^{100000} I_{b} \mathrm{~d} \lambda}
$$

Where $\rho_{\lambda}$ is the spectral reflectance of the solid, $I_{b}$ the spectral radiation of the blackbody at a given temperature and $\varepsilon$ is the total hemispheric emissivity of the solid.

\section{Experimental Techniques}

Ilmenite was supplied by an industry located on the Northeast coast of Brazil, in the city of Mataraca, where ilmenite occurs disseminated in coastal dunes. For the deposition, ilmenite was used in two configurations: in natura (original state of industrial processing) and after being sieved (53 microns), according to Medeiros ${ }^{13}$.

The samples were sintered in two methodologies: A (The samples were submitted to a temperature of $900^{\circ} \mathrm{C}$ at a rate of $5^{\circ} \mathrm{C}$ per minute) and $\mathrm{B}$ (The samples reached a temperature of $500^{\circ} \mathrm{C}$ at a rate of $20^{\circ} \mathrm{C}$ per minute and then reached the level of $900^{\circ} \mathrm{C}$ at a rate of $10^{\circ} \mathrm{C}$ per minute). Samples remained at high temperature processing for 120 minutes. Table 1 presents the sample nomenclature.

The ilmenite films were deposited by hollow cathode deposition on substrates of stainless steel AISI 304 cuts in the dimensions of $25 \mathrm{~mm} \times 25 \mathrm{~mm} \times 1 \mathrm{~mm}$.
Table 1. Nomenclature of the samples.

\begin{tabular}{|c|c|c|}
\hline Samples & Processing & Sinter \\
\hline Sample 1 & Sieve - $53 \mu \mathrm{m}$ & $\mathrm{B}$ \\
\hline Sample 2 & Sieve - $53 \mu \mathrm{m}$ & A \\
\hline Sample 3 & In natura & $\mathrm{A}$ \\
\hline Sample 4 & In natura & B \\
\hline
\end{tabular}

\subsection{Characterization of ilmenite}

To validate a new material in a specific application, a better understanding of the physical, chemical and mineralogical properties of this material is required. Chemical investigation by FRX made it possible to determine the chemical elements present in the ore as well as its most stable oxides using the Sequential X-Ray Fluorescence Spectrometer, Shimadzu XRF-1800 model.

The crystalline structure and identity of phases of ilmenite were studied by X-Ray diffraction using a diffractometer D2 Phaser Bruker, $\mathrm{Cu}-\mathrm{K} \alpha$ radiation, with tension and current of $30 \mathrm{kV}$ and $10 \mathrm{~mA}$, respectively. The tests were performed with a $2 \theta$ scan between $10^{\circ}$ and $75^{\circ}$ with a $0.02^{\circ} / \mathrm{s}$ pitch and a $1 \mathrm{~mm}$ gap $^{8}$. The diffractograms generated in the test and the quantitative analysis of the crystalline phases were analyzed using Bruker AXS software.

Transmittance analyzed in the infrared region were performed with a Shimadzu spectrophotometer IR Prestige-21 model for microstructural characterization of the ilmenite, highlighting its main vibrational bands in the suggested wavelength range. The experiments were carried out in the range between 4000 and $400 \mathrm{~cm}^{-1}$, with a resolution of $4 \mathrm{~cm}^{-1}$ and 20 accumulations.

Thermal analyses were performed on the samples in natura and sieve. Given the importance of predicting the behavior of the selective surface as a function of temperature, the purpose of this test is to determine the loss of mass and the thermal stability of the ilmenite. The equipment used was a TA Instruments SDT 650, performing the analysis of Thermogravimetric Analysis (TGA). The analysis was up to $1000^{\circ} \mathrm{C}$ with heating rate of $20^{\circ} \mathrm{C} / \mathrm{min}$ in argon atmosphere $\left(100 \mathrm{ml} \cdot \mathrm{min}^{-1}\right)$ using Platinum crucible.

\subsection{The deposition of ilmenite}

The conventional nitriding chamber was adapted for hollow cathode deposition configuration using a different configuration for the electrodes. The equipment consists of a stainless-steel vacuum chamber in the form of a cylinder, $300 \mathrm{~mm}$ in diameter and $400 \mathrm{~mm}$ high, with a side window for observation of the samples. A table composed of holes of $15 \mathrm{~mm}$ in diameter was used to place ilmenite tablets (target). The substrate designed to deposit the ilmenite film was placed on the sample holder. The pressure and voltage were adjusted until a high light discharge appeared between the two electrodes.

The hollow cathode discharge conditions were set at a voltage of $400 \mathrm{~V}$ and a current of $0.10 \mathrm{~A}$. The pressure inside the chamber was approximately $0.3 \mathrm{mbar}$ and the flow of oxygen gas $\left(\mathrm{O}_{2}\right)$ was kept constant at $30 \mathrm{sccm}$ at a working temperature of $180^{\circ} \mathrm{C}$. Thereafter, the conditions were fixed and maintained for 5 hours. The oxygen used was manufactured by White Martins and has $99.5 \%$ pure. 


\subsection{Characterization of the coatings}

Analysis of the optical properties of the ilmenite coatings were performed on the Shimadzu UV/Vis/NIR Spectrophotometer, UV 2600 model operating with the integration sphere accessory with a sweep from 220 to $1400 \mathrm{~nm}$. The surface morphology of the coating and the samples thicknesses were determined using a scanning electron microscope (SEM), FEI ESEM Quanta 450 model.

The determination of the surface roughness of the deposited films, was identified by the CCI MP non-contact optical profiling device, manufactured by Taylor Hobson, connected to a computerized unit containing the Talysurf CCI software (Taylor Hobson, 95 England) to obtain and analyze the data.

The optical characterization in the infrared region was analyzed on an Infrared Spectrometer, Spectrum 100, from Perkin Elmer. The spectrum was collected using the specular reflectance module, with an opening of $5 \mathrm{~mm}, 32$ scans and $4 \mathrm{~cm}^{-1}$ resolution.

\section{Results and Discussions}

\subsection{Characterization of ilmenite}

Table 2 shows composition of the most stable oxides present in the ilmenite under study, found in the X-ray fluorescence analyzes. Most of the iron and titanium oxides is noted. The differences between the compounds in the sample and the impurities contained in the mineral itself are related to the mineral origin of the ilmenite.

The analysis by X-ray diffraction show that is in mineral chemical constitution, the main phases found in the compound are ilmenite $\left(\mathrm{FeTiO}_{3}\right)$, followed by some peaks of Rutile $\left(\mathrm{TiO}_{2}\right)$. Using Bruker AXS software, it was possible to perform the refinement to estimate in percentage terms the quantification of the phases in the analyzed sample. Promptly, the highest concentration in this sample is $86.4 \%$ ilmenite and $13.6 \%$ rutile. The ICSD code of the letters found in the software for the ilmenite and rutile phases were 029209 and 039167 , respectively. The refined X-ray diffractometry spectrum of the ilmenite sample, with $\mathrm{FeTiO}_{3}$ structural formula is shown in Figure 1.

The identification of a sample through its infrared spectrum is observed in the inspection of the vibration modes of the molecules. In this spectrum, the absorption band at $3440 \mathrm{~cm}^{-1}$ is related to the stretching vibration mode of the hydroxyl groups, hydrogen bonds and chemically adsorbed water. The band around $2922 \mathrm{~cm}^{-1}$ indicates the presence of quartz in the ilmenite ore, which is understood by the presence of silicon dioxide, $\mathrm{SiO}_{2}$, in the chemical composition found by FRX. We can also notice the presence of a band close to $1035 \mathrm{~cm}^{-1}$, which is characteristic of the $\mathrm{O}-\mathrm{Ti}-\mathrm{O}$ bond, confirming the formation of titanium oxide, $\mathrm{TiO}_{2}$. The absorption band at $530 \mathrm{~cm}^{-1}$ can be attributed to the $\mathrm{Fe}-\mathrm{O}$ bond in the ilmenite $\left(\mathrm{FeTiO}_{3}\right)$ which indicates the formation of $\mathrm{Fe}_{2} \mathrm{O}_{3}$. These bands as well as the films obtained bands can be seen in the Table 3 .

The thermal analyses were performed in order to evaluate the influence of temperature on the material mass loss. Since selective surfaces are produced for high working temperatures, the thermal behavior analysis of the ilmenite can warn about the thermal stability at the collector outlet. The data obtained in the thermal analysis can be observed in Table 4. Note that, in natura ilmenite, sample 3, suffered a greater loss of mass and has lower thermal stability when compared with sample 2 , sieved ilmenite. It is noticed that

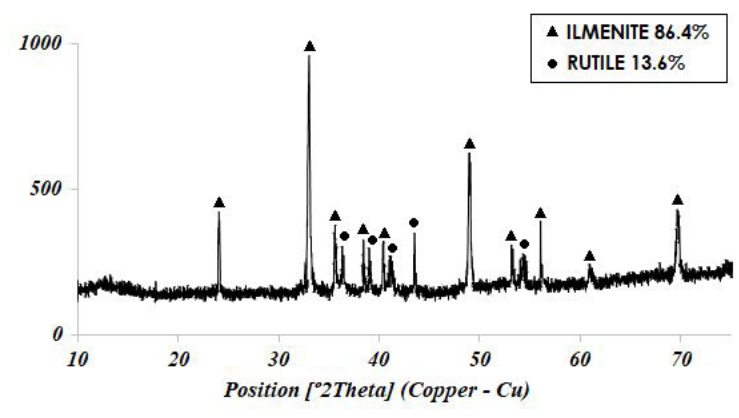

Figure 1. X-ray diffractometry spectrum refined by Bruker AXS software.

Table 2. Most stable oxides found in ilmenite.

\begin{tabular}{ccccccccc}
\hline Oxides & $\mathrm{TiO}_{2}$ & $\mathrm{Fe}_{2} \mathrm{O}_{3}$ & $\mathrm{Al}_{2} \mathrm{O}_{3}$ & $\mathrm{SiO}_{2}$ & $\mathrm{ZrO}_{2}$ & $\mathrm{Na}_{2} \mathrm{O}$ & $\mathrm{NbO}$ & $\mathrm{Others}$ \\
\hline \% atomic weight & 49,92 & 42,08 & 2,9 & 2,38 & 0,31 & 0,3 & 0,17 & 0,47 \\
\hline
\end{tabular}

Table 3. Vibrational bands in infrared spectrum.

\begin{tabular}{cccccc}
\hline Wavebands $\left(\mathrm{cm}^{-1}\right)$ & Ilmenite & Sample 1 & Sample 2 & Sample 3 & Sample 4 \\
\hline hydroxyl groups & 3440 & - & - & - & 2927 \\
\hline quartz & 2922 & - & - & 2000 & 2130 \\
\hline -O-H vibrations & 1630 & 1670 & 1600 & 1035 & 1050 \\
\hline O-Ti-O & 1035 & $812-1033$ & $830-1050$ & 635 & 630 \\
\hline Fe-O & 530 & 655 & 650 & - & - \\
\hline Fe & $472-493$ & - & - & & \\
\hline
\end{tabular}

Table 4. Total hemispheric absorptivity and emissivity and selectivity factor of the selected selective surfaces.

\begin{tabular}{ccccccccc}
\hline & \multirow{2}{*}{ Absortivity } & \multicolumn{2}{c}{ Emissivity } & & \multicolumn{2}{c}{ Loss mass (TGA) } & \multirow{2}{*}{ Selective factor } \\
\cline { 3 - 4 } \cline { 6 - 7 } & & $100^{\circ} \mathrm{C}$ & $500^{\circ} \mathrm{C}$ & & $100^{\circ} \mathrm{C}$ & $500^{\circ} \mathrm{C}$ & & \\
\hline Sample 2 & $87.84 \pm 2.24$ & $14.54 \pm 1.72$ & 14.71 & & $0.3 \%$ & $1.2 \%$ & 6.21 \\
\hline Sample 3 & $83.86 \pm 2.91$ & $13.49 \pm 2.04$ & 13.76 & & $0.4 \%$ & $2.0 \%$ & 6.21 \\
\hline
\end{tabular}




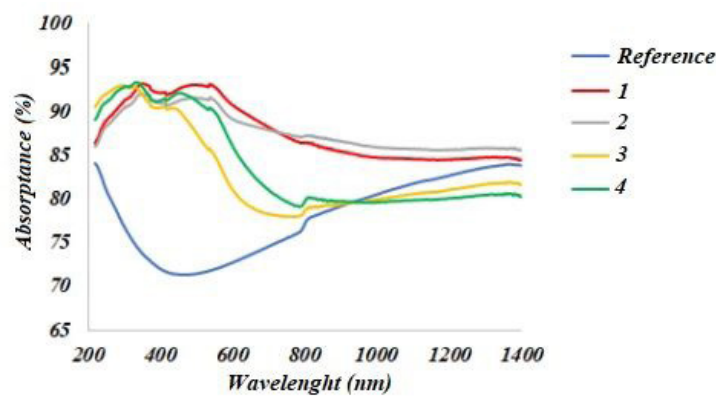

Figure 2. UV-Vis absorbance spectroscopy of ilmenite films deposited on 304 stainless steel substrates.

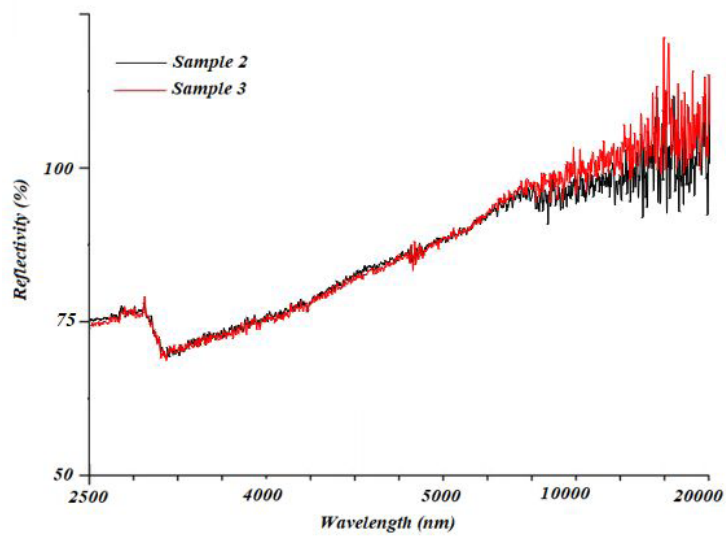

Figure 3. Reflectivity of the evaluated samples. a greater control of the material granulometry contributes to minimize the mass loss in medium and high temperatures, influencing the thermal stability of absorber films produced with this material.

\subsection{Characterization of the coatings}

The samples 2 and 3 presented the best results regarding solar absorptance in the UV/Vis/NIR regions. These results of solar absorptances were more than $85.0 \%$, as shown in Figure 2 .

The samples were also subjected to infrared radiation with measurements of attenuated total reflectance (ATR). Samples with better absorbance results were evaluated for films deposited on steel. After deposition, it is noted that the recurrent vibrational bands of the chemical water transformation processes and the presence of quartz, as shown in Table 3, did not form significant bands in the absorbent films. The vibrational bands characteristic of the $\mathrm{O}-\mathrm{Ti}-\mathrm{O}$ and $\mathrm{FeO}$ bonds in the ilmenite, remain in evidence on the selective surface.

Figure 3 shows the results for samples 2 and 3 evaluated in the infrared radiation ranges. These were the samples which showed better absorbance.

From the results presented by Figure 3 and Equation 2, the total hemispheric emissivity of the samples was calculated at a temperature of $100^{\circ} \mathrm{C}$ and theoretical estimate was calculated at a temperature of $500^{\circ} \mathrm{C}$. The calculated values for the emissivity, together with the experimental values of the absorptivity are shown in Table 4

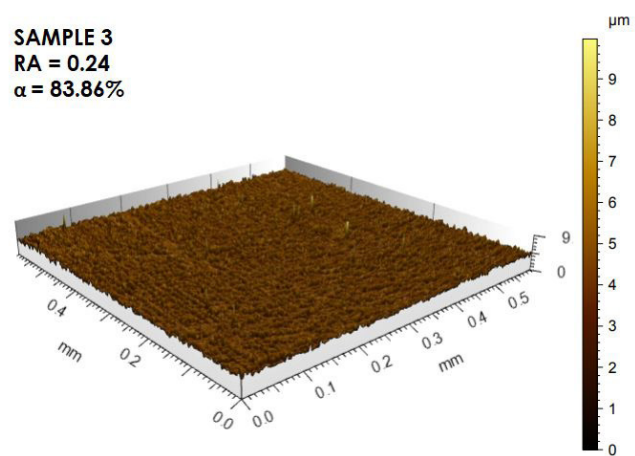

(a)
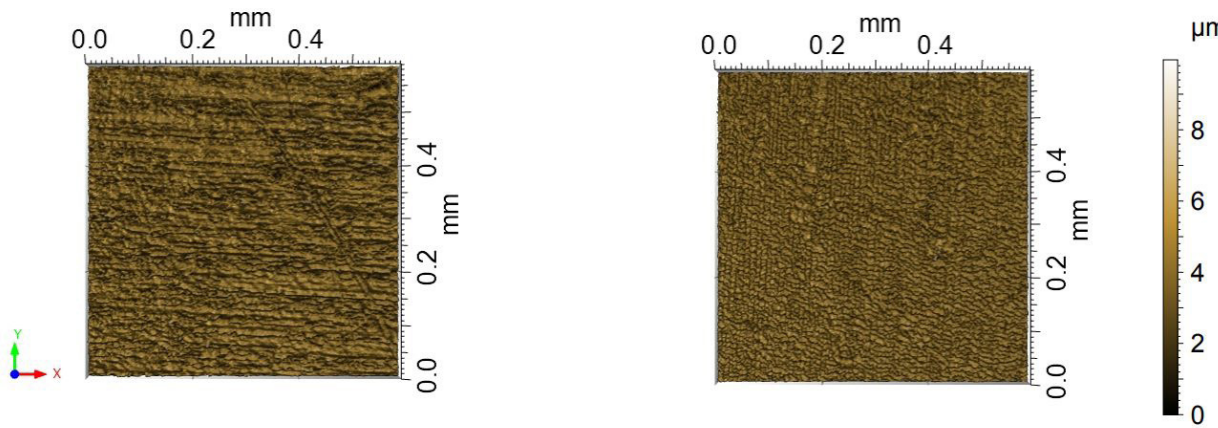

(b)

Figure 4. Samples profilometry. Perspective view (a) and top view (b). 


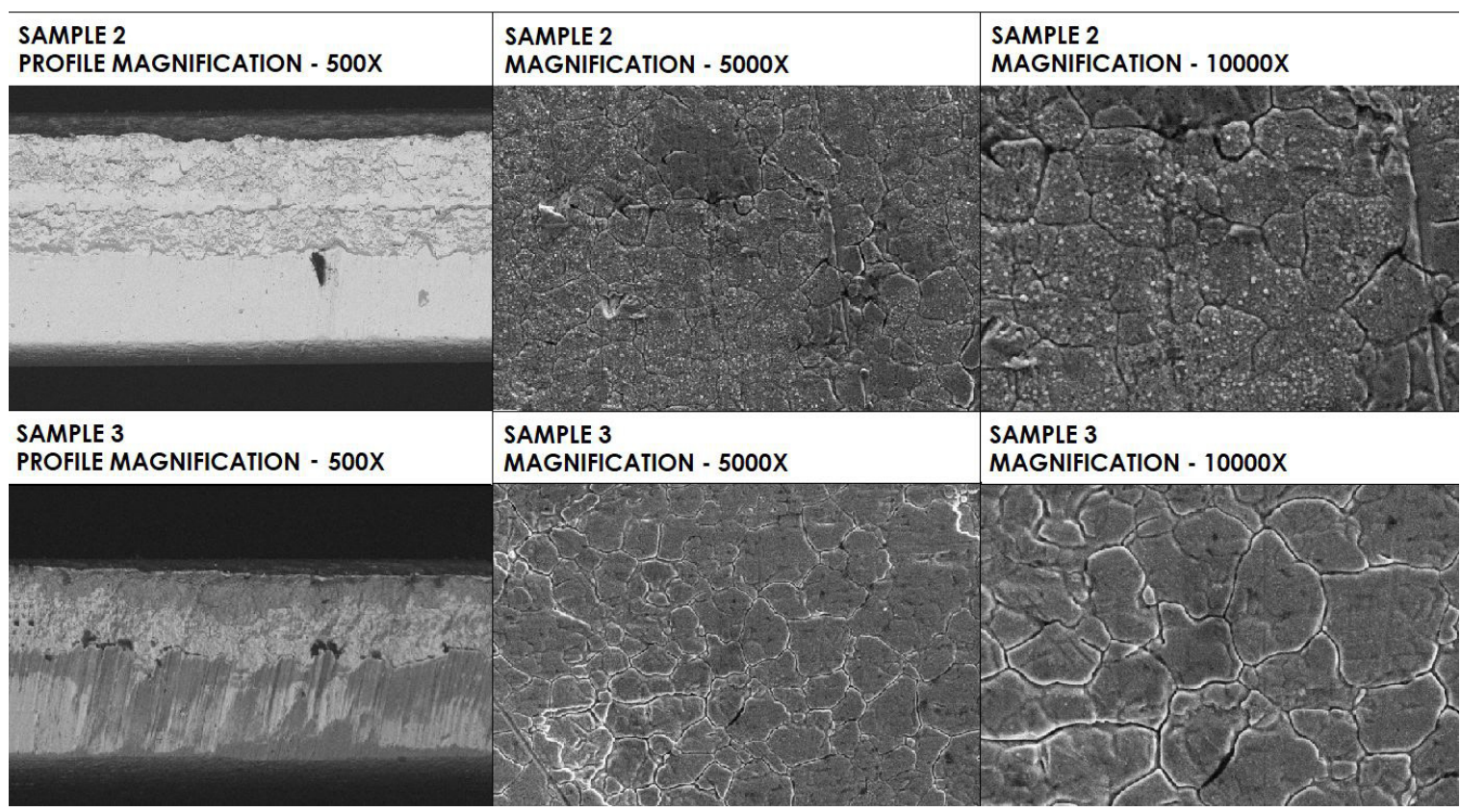

Figure 5. Micrographs of the samples that obtained the best results in absorbance and emittance.

Table 5. Ra parameter of absorber films.

\begin{tabular}{cc}
\hline Samples & $\mathrm{Ra}(\mu \mathrm{m})$ \\
\hline Sample 2 & 0,44 \\
\hline Sample 3 & 0,24 \\
\hline
\end{tabular}

According to the studies by Krenzinger ${ }^{14}$ and Xiao et al. ${ }^{5}$, a selective surface for photothermal purposes must have a selectivity factor greater than 5.67 , but it is necessary that the solar absorbance is greater than $85 \%$ and the emittance is less than $15 \%$. Within these criteria, sample 2 are presented as moderately selective.

The coatings roughness of the samples 2 and 3 are showed by Table 5 .

Note that sample 3 that obtained better results in terms of emissivity has a less rough surface. In addition to the Ra parameter of the film surface, analysis by profilometry, allowed to obtain 3D images of the film surface. Figure 4 shows the surface roughness of the sample 2 and sample 3 , respectively.

SEM analysis allowed the characterization of the surfaces of absorbent films produced from the mineral under study, ilmenite, in relation to its morphology. Figure 5 shows the ilmenite films that were deposited on a steel substrate in different magnitudes.

From the imaging of the film substrate profile, the thickness of the sample 2 coating was approximately $368 \mathrm{~nm}$. In sample 3, the measured thickness was approximately $204 \mathrm{~nm}$. Note also a diffusion zone caused by the intensified plasma from the deposition technique used.

The micrographs of the present study verified that the ilmenite grains have slightly altered edges and good geometric uniformity. The illustrated films showed a porous structure with grains on the micro scale. The surfaces contain many spheroids with very small diameters that can be seen in the images of greater magnitude in Figure 5. Protsenko et al. ${ }^{15}$ observed that this phenomenon occurs when the thickness of the coatings is less than $10 \mu \mathrm{m}$, which coincides with the films presented.

\section{Conclusions}

Selective surfaces of ilmenite on stainless steel substrate were prepared by chemical deposition by hollow cathode, for photothermal applications, with a selectivity factor of 6.21. The raw material used in this project was extracted and processed in the state of Paraíba, Brazil, and the deposition process employed was an adaptation to the thermo-chemical treatment of plasma nitriding developed by UFERSA, a partner university in this research.

The studied ilmenite presented in its composition the majority presence of iron and titanium in the solid product. The results presented in its characterization showed that the compound has few recurring impurities of its mineral origin.

The deposition technique used was satisfactory for stainless steel substrates. The films were deposited uniformly and with a moderate control of their thickness, from the deposition parameters and the distance between the target and the sample holder.

This work showed that it is possible to use ilmenite as a precursor material for selective surfaces for photothermal purposes. The absorbent films produced were moderately selective. Sample 2, which obtained the best results of absorbance, greater than $85 \%$ and emission less than $15 \%$.

\section{References}

1. Medeiros IDM, Silva JF No, Leite KS, da Silva AKB, Gomes KC. Eletrodeposição de filmes de cromo negro em substratos de cobre para absorção solar. Encicl Biosf. 2017;14(26):1370-9. 
2. Cao F, McEnaney K, Chen G, Ren Z. A review of cermetbased spectrally selective solar absorbers. Energy Environ Sci. 2014;7(5):1615-27.

3. Kennedy CE. Review of mid-to high-temperature solar selective absorber materials. Golden, CO: National Renewable Energy Lab.; 2002.

4. Aguilar M, Barrera E, Palomar-Pardavé M, Huerta L, Muhl S. Characterization of black and white chromium electrodeposition films: surface and optical properties. J Non-Cryst Solids. 2003;329(1-3):31-8

5. Xiao X, Miao L, Xu G, Lu L, Su L, Su Z, et al. A facile process to prepare copper oxide thin films and solar selective absorbers. Appl Surf Sci. 2011;257(24):10729-36.

6. Çengel YA, Ghajar AJ. Heat and mass transfer: fundamentals and applications. New Delhi: Tata McGraw-Hill; 2011.

7. Freitas RS. Deposição e caracterização de nitreto de titânio com diferentes gaiolas catódicas em substrato de silício [dissertation]. Teresina: Programa de Pós-graduação em Engenharia de Materiais, Instituto Federal de Educação, Ciência e Tecnologia do Piauí; 2016.

8. Rodbari RJ, Jamshidi LCLA, Nascimento L, Téllez DAL, Hernández EP. Caracterização da ilmenita por difração de
raios-X e microscopia eletrônica de varredura. Rev Colomb Mater. 2015;(7):82-93.

9. Barth TFW, Posnjak E. The crystal structure of Ilmenite. Zeit F Krist. 1934;88:265-70.

10. Ribeiro RAP. Investigação teórica de materiais com estrutura ilmenita [dissertation]. Ponta Grossa: Universidade Estadual de Ponta Grossa; 2015.

11. Silva JF No. Desenvolvimento de superfícies seletivas para coletores solares com deposição multicamadas de $\mathrm{Cr}$ e $\mathrm{SiO}_{2}$ [thesis]. João Pessoa: Universidade Federal da Paraíba; 2017.

12. Modest MF. Radiative heat transfer. 3rd ed. Oxford: Academic Press; 2013.

13. Medeiros IDM. Estudo da capacidade intrínseca de absorção solar da cinza do bagaço de cana-de-açúcar. 1. ed. Porto Alegre: Revolução eBooks; 2018.

14. Krenzinger A. Superfícies seletivas para conversão térmica da energia solar, óxido de cobre sobre cobre [dissertation]. Porto Alegre: Universidade Federal do Rio Grande do Sul; 1979.

15. Protsenko VS, Danilov FI, Gordiienko VO, Kwon SC, Kim M, Lee JY. Electrodeposition of hard nanocrystalline chrome from aqueous sulfate trivalent chromium bath. Thin Solid Films. 2011;520(1):380-3. 